\title{
Efeitos da fitase no desempenho e na qualidade da carne de frangos de corte ${ }^{1}$
}

\section{Effects of phytase on the performance and broiler meat quality}

\author{
Sandra Regina Brunelli²; João Waine Pinheiro ${ }^{3 *}$; Ana Maria Bridi'; \\ Nilva Aparecida Nicolao Fonseca ${ }^{4}$; Caio Abércio Silva ${ }^{3}$; Alexandre Oba ${ }^{3}$
}

\begin{abstract}
Resumo
Foram avaliados os efeitos da enzima fitase sobre o desempenho, o rendimento de carcaça e a qualidade da carne (oxidação lipídica dos músculos da coxa a e peito) de frangos de corte submetidos a dietas formuladas à base de milho, farelo de soja e farelo de gérmen de milho desengordurado (FGMD), um ingrediente com alta concentração de ácido fítico. Foram utilizados 300 frangos de corte machos, com quatro dias de idade, distribuídos em um delineamento experimental inteiramente casualizado, com três tratamentos (correspondentes a três níveis dietéticos de fitase: 0; 750 e $1500 \mathrm{FTU} / \mathrm{kg}$ de ração) e dez repetições com dez aves cada. Foi utilizado um programa alimentar em três fases, inicial (4 a 21 dias de idade), crescimento (22 a 35 dias) e terminação (36 a 42 dias). Os níveis de fitase não afetaram o desempenho e o rendimento das carcaças e suas partes, mas aumentaram os valores de TBARS do músculo da coxa e do peito refrigerados, indicando piora da oxidação lipídica da carne.

Palavras-chave: Ácido fítico, alimento alternativo, enzima, farelo de gérmen de milho desengordurado, TBA
\end{abstract}

\begin{abstract}
The effects of phytase on the performance, carcass yield and on the meat quality (lipid oxidation of drumstick and breast muscle) were evaluated on broilers submitted to diets containing corn, soybean and defatted corn germ meal, an ingredient with high level of phytic acid. Three hundred male broilers, with $4 \mathrm{~d}$ of age, were distributed in a completely randomized design with three treatments (represented by three levels of phytase in the diet: 0; 750 e $1500 \mathrm{FTU} / \mathrm{kg}$ of ration), with ten replicates and ten broilers per experimental unit. The feeding program was divided in three periods, according the age, starting ( 4 to $21 \mathrm{~d}$ ), growing ( 22 to $35 \mathrm{~d}$ ) and finishing phases ( 36 to $42 \mathrm{~d}$ ). There were no phytase's effects on growth performance and carcass yield. There was an increasing the TBARS values to the refrigerated drumstick and the breast muscles, corresponding a negative effect on the lipid oxidation of meat.
\end{abstract}

Key words: Alternative feed, defatted corn germ meal, enzyme, phytic acid, TBA

1 Parte da tese de Doutorado em Ciência Animal, do primeiro autor, Universidade Estadual de Londrina, UEL, Londrina, PR.

2 Prof ${ }^{\mathrm{a}}$. Dr ${ }^{\mathrm{a}}$. do Curso de Medicina Veterinária, Faculdade de Ciências Sociais e Agrárias de Itapeva, FAIT, Itapeva, SP. E-mail: sandrareginabrunelli@hotmail.com

${ }^{3}$ Profs. Drs. do Dept ${ }^{0}$ de Zootecnia. Universidade Estadual de Londrina, UEL, Londrina, PR. E-mail: jwaine@uel.br; ambridi@ uel.br; casilva@uel.br; oba@uel.br

${ }^{4}$ Prof $^{\mathrm{a}}$. Dr ${ }^{\mathrm{a}}$ Aposentada do Dept ${ }^{\mathrm{o}}$ de Zootecnia, UEL, Londrina, PR. E-mail: nilva@uel.br

* Autor para correspondência 


\section{Introdução}

No Brasil, as rações dos frangos são formuladas basicamente pelo binômio milho e farelo de soja, ingredientes cujo fósforo está presente principalmente na forma de ácido fítico (AF) (KASIM; EDWARDAS, 1998).

A função do AF nas células vegetais está relacionada com a sinalização da transmembrana e a mobilização do cálcio para as reservas intracelulares (XU; LIU; PRESTWICH, 2005). Sua molécula possui elevado poder de quelatação (KESHAVARZ, 1999), tendo afinidade por minerais como o fósforo, cálcio, ferro, zinco, cobre, potássio e manganês (LIU; CHENG; ZHANG, 2005), além de proteínas, aminoácidos (FEBLES et al., 2002) e outros elementos, sendo considerado assim um antinutriente para frangos, pois interfere negativamente na disponibilidade destes, bem como na utilização da energia da dieta (KESHAVARZ, 1999).

O organismo das aves é ineficiente na secreção da enzima fitase para disponibilizar o fósforo e outros componentes complexados da molécula de AF dos ingredientes vegetais (RAVINDRAN et al., 2006). Todavia, vários estudos, como de Ekholm et al. (2003), demonstraram que estes quelatos podem ser hidrolisados no trato gastrointestinal através da ação da fitase exógena, disponibilizando componentes de menor peso molecular como o mioinositol fostato, inositol e fósforo inorgânico (GREINER; CARLSSON; ALMINGER, 2000), além de outros minerais metálicos.

Devido a habilidade do AF em quelatar o ferro, em especial, algumas pesquisas investigaram o potencial antioxidante desta molécula em sistemas alimentares envolvendo frangos de corte (SOARES, 1998; LEAL, 2000), contudo os estudos ainda são escassos nesta espécie, demandando confirmações de sua efetividade (PILLAI et al., 2006; REZAEI et al., 2007). Por outro lado, os efeitos do AF dietético na qualidade da carne de suínos foram positivos, prevendo a oxidação da carne e suas conseqüências, conforme descreveram Gebert et al. (1999a; 1999b), Shelton et al.(2004) e Harbach et al. (2007).

Sabe-se que o ácido fítico inibe a peroxidação lipídica da carne, acelerando a auto-oxidação de íons ferrosos para íons férricos, formando quelatos férricos, inativando-os cataliticamente. Os lipídios da carne podem ser oxidados na presença de oxigênio através de reações de radicais livres que geram peróxidos e hidroperóxidos, determinando a rancificação oxidativa (St. ANGELO, 1996).

Neste particular, o farelo de gérmen de milho desengordurado (FGMD), produto da extração do óleo do gérmen de milho, que apresenta elevada concentração de ácido fítico (BRUNELLI et al., 2006), 2,81\% segundo Fukuji et al. (2008), pode representar um importante ingrediente para a composição da ração de frangos de corte para este fim.

Assim, este trabalho foi realizado com o objetivo de analisar o efeito da enzima fitase sobre as características de desempenho, rendimento de carcaça e a oxidação lipídica dos músculos da coxa e do peito de frangos alimentados com rações contendo milho, farelo de soja e farelo de gérmen de milho desengordurado.

\section{Material e Métodos}

O experimento foi conduzido no setor de Avicultura da Fazenda Escola da Universidade Estadual de Londrina. Foram utilizados 300 frangos de corte machos, com quatro dias de idade, alojados em galpão convencional, dividido em 30 boxes, equipados com comedouros tubulares e bebedouros pendulares, sendo adotados os manejos tradicionalmente empregados nas granjas comerciais, com água e ração à vontade.

No início do experimento os frangos foram individualmente pesados e distribuídos aleatoriamente nos boxes de acordo com o peso médio (SAKOMURA; ROSTAGNO, 2007). 
Os tratamentos experimentais consistiram, para cada uma das suas fases de desenvolvimento, do fornecimento de rações à base de milho, farelo de soja e farelo de gérmen de milho desengordurado (FGMD) suplementadas ou não com fitase, sendo uma ração controle ( $0 \mathrm{FTU} / \mathrm{kg})$, isenta da enzima, e duas outras suplementadas com fitase, contendo 750 e $1500 \mathrm{FTU} / \mathrm{kg}$ de ração.

Os frangos foram dispostos em um delineamento experimental inteiramente casualizado, com três tratamentos, com dez repetições, com dez frangos por unidade experimental.

As rações experimentais (Tabela 1) foram formuladas considerando as exigências nutricionais para frangos de corte em três fases, inicial $\left(4^{\circ}\right.$ a $21^{\circ}$ dias de idade), de crescimento $\left(22^{\circ}\right.$ a $35^{\circ}$ dias $)$ e final $\left(36^{\circ}\right.$ a $42^{\circ}$ dias), obedecendo as recomendações e a composição dos ingredientes citadas por Rostagno et al. (2005), à exceção da composição do FGMD, cujos valores nutricionais considerados corresponderam aos citados por Brunelli et al. (2006).

Foi utilizado o produto NATUPHOS $10.000 \mathrm{G}^{\circledR}$ como fonte de fitase, não sendo considerada a sua matriz nutricional na formulação das rações.

Aos 21, 35 e 42 dias de idade foram realizadas pesagens das aves e das rações para a obtenção dos dados de ganho de peso, consumo de ração e conversão alimentar.
Aos 43 dias de idade, após jejum de cinco horas, foram abatidos 30 frangos, um de cada boxe, representando o peso vivo médio da unidade experimental, totalizando dez aves por tratamento. Foram determinados o peso vivo ao abate, o peso da carcaça, e os pesos do peito, coxa, perna e asa, todos com pele, em gramas por quilo de carcaça $(\mathrm{g} / \mathrm{kg})$.

Considerou-se como carcaça, o frango abatido, depenado, eviscerado e mantido com os pés e cabeça. Após a pesagem das carcaças e de suas partes, foi coletado o músculo do peito (Pectoralis major) e parte do músculo da coxa (Peroneus longus) para a determinação da oxidação lipídica através da técnica de substancias reativas ao ácido tiobarbitúrico (TBARS), conforme Tarladgis, Pearson e Dugan Junior (1964), modificada por Crackel et al. (1988). Cada músculo foi seccionado em duas amostras de aproximadamente $70 \mathrm{~g}$, uma amostra permaneceu refrigerada a temperatura de $4^{\circ} \mathrm{C}$, protegida da luz durante sete dias e a outra amostra foi mantida em temperatura de congelamento $\left(-20^{\circ} \mathrm{C}\right)$, protegida da luz, durante 60 dias. As análises foram realizadas em duplicata, em nove amostras de cada tratamento e os produtos da oxidação quantificados em equivalentes malonoaldeido (mg MDA/kg de músculo).

As médias obtidas foram submetidas à análise estatística através do programa SAEG (UFV, 2005), sendo realizadas análises de variância e, quando os valores de $\mathrm{F}$ foram significativos $(\mathrm{P}<0,05)$, foi aplicado o teste de Dunnett (5\%), comparando os resultados dos tratamentos com os parâmetros do grupo tratado com ração com 0 FTU/kg. 
Tabela 1. Composição alimentar das rações experimentais

\begin{tabular}{lccc}
\hline \multirow{2}{*}{\multicolumn{1}{c}{ Ingrediente }} & \multicolumn{3}{c}{ Ração $(\mathrm{g} / \mathrm{kg}$ de matéria natural) } \\
\cline { 2 - 4 } & Inicial & Crescimento & Final \\
\hline Milho & 365,69 & 400,88 & 440,06 \\
Farelo de soja & 339,22 & 297,03 & 258,50 \\
FGMD & 200,00 & 200,00 & 200,00 \\
Óleo de soja & 55,57 & 64,19 & 64,30 \\
Fosfato bicálcio & 18,72 & 17,38 & 15,98 \\
Calcário & 7,71 & 7,34 & 6,97 \\
Sal comum & 3,00 & 3,00 & 3,00 \\
DL-Metionina & 3,17 & 3,13 & 3,03 \\
L-Lisina HCl & 2,81 & 3,06 & 3,57 \\
Supl. Vitamínico + Mineral ${ }^{1}$ & 4,00 & 4,00 & 4,00 \\
Composição nutricional & & & \\
Energia metabolizável $(\mathrm{kcal} / \mathrm{kg})(\mathrm{kcal} / \mathrm{kg})$ & 3.000 & 3.100 & 3.150 \\
Proteína bruta $(\mathrm{g} / \mathrm{kg})$ & 210,0 & 194,0 & 180,3 \\
Cálcio $(\mathrm{g} / \mathrm{kg})$ & 8,8 & 8,2 & 7,6 \\
Fósforo disponível $(\mathrm{g} / \mathrm{kg})$ & 4,4 & 4,1 & 3,8 \\
Metionina digestível $(\mathrm{g} / \mathrm{kg})$ & 5,7 & 5,5 & 5,2 \\
Met.+ Cistina digestível $(\mathrm{g} / \mathrm{kg})(\mathrm{g} / \mathrm{kg})$ & 8,1 & 7,7 & 7,3 \\
Lisina digestível $(\mathrm{g} / \mathrm{kg})$ & 11,5 & 10,7 & 10,2 \\
\hline
\end{tabular}

${ }^{1}$ Suplemento vitamínico+mineral. Composição por kg de produto: Vit. A 2.500.000 UI; Vit. D3 562.500 UI; Vit. E 5.677 mg; Vit. K3 750 mg; Vit B1 503 mg; Vit. B2 1.305 mg; Vit. B6 1.050 mg; Vit. B12 4.087 mcg; Ac. Pantotênico 4.087 mg, Ac. Nicotínico $6.315 \mathrm{mg}$; Ac. Fólico 284,250 mg; Manganês $13.642 \mathrm{mg}$; Zinco $12.502 \mathrm{mg}$; Ferro $12.517 \mathrm{mg}$; Cobre 1.500 mg; Iodo $102 \mathrm{mg}$; Selênio 38 mg; Cobalto 244 mg; Colina 6.682 mg; Biotina 41 mg, Veículo q.s.p - 1.000g

Fonte: Elaboração dos autores.

\section{Resultados e Discussão}

A suplementação das rações com fitase não determinou efeitos $(\mathrm{P}>0,05)$ no ganho de peso, no consumo de ração e na conversão alimentar dos frangos de corte, em relação à ração isenta da enzima (Tabela 2).

Experimentos conduzidos por Rezaei et al. (2007) e Vieira et al. (2007) também não observaram vantagens para a adição da fitase exógena na ração sobre o desempenho de frangos de corte. No entanto, Munaro et al. (1996), Tejedor, Albino e Rostagno (2001) e Pintar et al. (2004) verificaram efeitos positivos dos níveis crescentes de fitase na dieta sobre o desempenho dos frangos em crescimento e terminação, sendo que os primeiros autores recomendaram como nível ótimo a inclusão de 500 a $700 \mathrm{FTU} / \mathrm{kg}$. Por sua vez, Pintar et al. (2004), ao fornecerem aos frangos rações formuladas a base de milho, trigo, cevada, triticale, adicionadas de 0,500 e $1000 \mathrm{FTU} / \mathrm{kg}$, obtiveram aumento de $6 \%$ no ganho de peso e 7\% no consumo para a suplementação de $1000 \mathrm{FTU} / \mathrm{kg}$, em relação a dietas isentas da enzima.

De acordo com Tejedor, Albino e Rostagno (2001), Aksakal e Bilal (2002) e Cowieson e Ravidran (2007), a fitase adicionada na ração degrada parcialmente a parede celular dos alimentos de origem vegetal, ocasionando melhora na digestibilidade dos nutrientes, promovendo um aumento no consumo da ração e no ganho de peso dos frangos. 
Tabela 2. Efeito da inclusão da enzima fitase na ração sobre desempenho dos frangos de corte.

\begin{tabular}{|c|c|c|c|c|c|}
\hline \multirow{2}{*}{ Características } & \multicolumn{3}{|c|}{ Fitase (FTU/kg) } & \multirow{2}{*}{$\mathrm{CV}(\%)$} & \multirow{2}{*}{ Dunnett } \\
\hline & 0 & 750 & 1500 & & \\
\hline \multicolumn{6}{|c|}{4 a 21 dias de idade } \\
\hline Ganho de peso (kg) & 0,833 & 0,842 & 0,866 & 5,07 & NS \\
\hline Consumo de ração $(\mathrm{kg})$ & 1,172 & 1,159 & 1,190 & 4,31 & NS \\
\hline Conversão alimentar $(\mathrm{kg} / \mathrm{kg})$ & 1,408 & 1,378 & 1,375 & 4,10 & NS \\
\hline \multicolumn{6}{|c|}{22 a 35 dias de idade } \\
\hline Ganho de peso $(\mathrm{kg})$ & 1,251 & 1,284 & 1,240 & 6,02 & NS \\
\hline Consumo de ração $(\mathrm{kg})$ & 2,115 & 2,136 & 2,090 & 7,23 & NS \\
\hline Conversão alimentar $(\mathrm{kg} / \mathrm{kg})$ & 1,691 & 1,665 & 1,685 & 4,95 & NS \\
\hline \multicolumn{6}{|c|}{36 a 42 dias de idade } \\
\hline Ganho de peso $(\mathrm{kg})$ & 0,355 & 0,374 & 0,354 & 10,67 & NS \\
\hline Consumo de ração (kg) & 0,863 & 0,876 & 0,869 & 5,19 & NS \\
\hline Conversão alimentar $(\mathrm{kg} / \mathrm{kg})$ & 2,463 & 2,351 & 2,466 & 8,19 & NS \\
\hline \multicolumn{6}{|c|}{4 a 42 dias de idade } \\
\hline Ganho de peso $(\mathrm{kg})$ & 2,440 & 2,500 & 2,460 & 4,82 & NS \\
\hline Consumo de ração $(\mathrm{kg})$ & 4,151 & 4,171 & 4,149 & 3,73 & NS \\
\hline Conversão alimentar $(\mathrm{kg} / \mathrm{kg})$ & 1,70 & 1,69 & 1,69 & 3,04 & NS \\
\hline
\end{tabular}

$\mathrm{CV}(\%)=$ Coeficiente de variação; $\mathrm{NS}=$ Não significativo

Fonte: Elaboração dos autores.

Segundo Qian, Kornegay e Conner (1996), a eficiência da fitase nos parâmetros de desempenho é aumentada quando esta participa de dietas que contém baixos níveis de fósforo disponível, sendo sua função inibida quando estes níveis atendem as exigências nutricionais dos frangos (GODOY; HERNÁNDEZ; CHICCO, 2002). A quantidade de fósforo disponível contida nas rações utilizadas neste experimento foi estimada para atender as recomendações mínimas estabelecidas por Rostagno et al. (2005), o que pode ter sido determinante para que não houvesse efeitos no consumo de ração e no ganho de peso dos frangos.

Ao abate, os animais, por conta de um mesmo desempenho obtido, apresentaram mesmos rendimentos de carcaças e de suas partes (Tabela 3), concordando com os resultados obtidos por Pillai et al. (2006), Rezaei et al. (2007) e Vieira et al. (2007), que também não detectaram efeitos significativos da fitase exógena nas características de carcaça dos frangos de corte.
Quanto à oxidação lipídica da carne, a inclusão de $1500 \mathrm{FTU} / \mathrm{kg}$ de ração determinou diferença significativa $(\mathrm{P} \leq 0,05)$ nos valores de TBARS no músculo da coxa e do peito refrigerados, em relação à ração isenta da enzima (Tabela 4).

Considerando que quanto maior o valor de TBARS, maior é a oxidação lipídica, verificou-se que a adição da enzima fitase na ração influenciou negativamente a estabilidade dos lipídios das carnes refrigeradas. Este resultado está coerente com os obtidos por Gebert et al. (1999b), que testando quatro rações (controle, controle + fitase, controle + vitamina E e controle + fitase + vitamina E), também verificaram efeito negativo da fitase na oxidação lipídica e na coloração da carne de suínos, atribuindo este efeito ao aumento da disponibilidade de minerais, principalmente do ferro. 
Tabela 3. Efeito da inclusão da enzima fitase na ração no peso vivo de abate $(\mathrm{g})$, rendimento da carcaça $(\mathrm{g} / \mathrm{kg}$ peso vivo ao abate) e suas partes ( $\mathrm{g} / \mathrm{kg}$ de carcaça) dos frangos de corte.

\begin{tabular}{|c|c|c|c|c|c|}
\hline \multirow{2}{*}{ Característica } & \multicolumn{3}{|c|}{ Fitase (FTU/kg) } & \multirow{2}{*}{$\mathrm{CV}(\%)$} & \multirow{2}{*}{ Dunnett } \\
\hline & 0 & 750 & 1500 & & \\
\hline Peso vivo ao abate & 2560,0 & 2580,0 & 2560,0 & 3,99 & NS \\
\hline Rendimento da carcaça & 822,7 & 820,4 & 834,2 & 1,89 & NS \\
\hline Rendimento do peito & 276,5 & 280,6 & 280,0 & 5,87 & NS \\
\hline Rendimento da coxa & 152,5 & 149,8 & 143,3 & 7,26 & NS \\
\hline Rendimento da perna & 125,1 & 125,2 & 128,1 & 7,49 & NS \\
\hline Rendimento da asa & 106,4 & 103,7 & 103,9 & 5,11 & NS \\
\hline
\end{tabular}

$\mathrm{CV}(\%)=$ Coeficiente de variação; $\mathrm{NS}=$ Não significativo.

Fonte: Elaboração dos autores.

Tabela 4. Efeito da adição da enzima fitas na ração nos valores de TBARS (mg de MDA/kg) dos músculos da coxa e do peito dos frangos de corte.

\begin{tabular}{|c|c|c|c|c|c|}
\hline \multirow{2}{*}{ TBARS } & \multicolumn{3}{|c|}{ Fitase (FTU/kg) } & \multirow{2}{*}{$\mathrm{CV}(\%)$} & \multirow{2}{*}{ Dunnett } \\
\hline & 0 & 750 & 1500 & & \\
\hline Coxa refrigerada & 0,348 & 0,421 & $0,521^{*}$ & 33,36 & $\mathrm{~S}$ \\
\hline Peito refrigerado & 0,208 & 0,286 & $0,341 *$ & 30,15 & S \\
\hline Coxa congelada & 0,238 & 0,185 & 0,222 & 27,43 & NS \\
\hline Peito congelado & 0,143 & 0,178 & 0,198 & 29,15 & NS \\
\hline
\end{tabular}

*Valor diferente $(\mathrm{P}<0,05)$ em relação à ração com $0 \mathrm{FTU} / \mathrm{kg}$ pelo teste de Dunnett; $\mathrm{CV}(\%)=$ Coeficiente de variação; $\mathrm{S}=$ Significativo; NS= Não Significativo

Fonte: Elaboração dos autores.

Ao adicionar a enzima fitase nas rações de suínos, Stahl, Han e Roneker (1999) observaram aumento na concentração do ferro sanguíneo. Sabese que cor da carne é definida pelos seus pigmentos desoximioglobina e oximioglobina, que são proteínas heme que possuem ferro ferroso na sua estrutura molecular. Estas proteínas se transformam em metamioglobina, uma proteína rica em ferro férrico. A conversão do ferro ferroso, presente na desoximioglobina e na oximioglobina, em ferro férrico, presente na metamioglobina, ocorre a partir de um processo oxidativo, que causa a rancidez na carne. Portanto, a oxidação lipídica da carne está correlacionada positivamente com a oxidação dos pigmentos que a constitui, principalmente o ferro.

Neste experimento não se constatou, através do TBARS, efeito significativo $(\mathrm{P}>0,05)$ da fitase na oxidação lipídica das carnes congeladas, o que se deve, provavelmente, à temperatura de congelamento, que foi efetiva em manter a maior estabilidade lipídica.

Os valores de TBARS das carnes refrigeradas da coxa e do peito dos frangos alimentados com a ração contendo a maior inclusão da enzima sugere que a fitase, ao romper a molécula de ácido fítico, libera ions metálicos (ferro total e heme) que catalisam peroxidação, fazendo com que o AF perca a sua função antioxidante (GRAF ; EATON, 1990).

A ação antioxidante do ácido fítico em carnes foi constatada por Lee e Hendricks (1995) e também por Soares et al. (2004), quando adicionaram pequenas quantidades do mesmo diretamente na carne bovina e de frangos durante o seu processamento. Harbach et al. (2007) também determinaram efeito antioxidante do ácido fítico em carnes de suínos alimentados com ração contendo $40 \%$ de farelo de germén de milho desengordurado, alimento rico em ácido fítico, constatando redução de $62,9 \%$ nos 
valores de TBARS da carne refrigerada e $27,4 \%$ na carne congelada.

\section{Conclusão}

A adição da fitase em rações de frangos de corte não teve efeito sobre as características de desempenho e de rendimento de carcaça e suas partes, mas aumentou os valores de TBARS dos músculos da coxa e do peito resfriados, indicando uma ação na piora da oxidação lipídica.

\section{Referências}

AKSAKAL, D. H.; BILAL, T. Effects of microbial phytase and 1,25-dihydroxycholecalciferol on the absorption of minerals from broiler chicken diets containing different levels of calcium. Acta Veterinaria. Hungarica, Instambul, v. 50, n. 3, p. 307-313, 2002.

BRUNELLI, S. R.; PINHEIRO, J. W.; SILVA, C. A.; FONSECA, N. A. N.; OLIVEIRA, D. D.; CUNHA, G. E.; SOUZA, L. F. A. Inclusão de farelo de gérmen de milho desengordurado na alimentação de frangos de corte. Revista Brasileira de Zootecnia, Viçosa, MG, v. 35, n. 4, p. 1349-1358, 2006.

COWIESON, A. J.; RAVINDRAN, V. Effect of phytic acid and phytase on the flow and amino acid composition of endogenous protein at the terminal ileum of growing broiler chickens. British Journal of Nutrition, London, v. 98, n. 4, p. 745-752, 2007.

CRACKEL, R. L.; GRAY, I. J.; PEARSON, A. M.; BOOREN, A. M.; BUCKLEY, D. J. Some further observations on the TBA test as an index of lipid oxidation in meats. Food Chemistry, Whiteknights, v. 28, n. 3, p. 187-196, 1988.

EKHOLM, P.; VIRKKI, L.; YLINEN, M.; JOHANSSON, L. The effect of phytic acid and some natural chelating agents on the solubility of mineral elements in oat bran. Food Chemistry, Whiteknights, v. 80, n. 2, p. 165-170, 2003.

FEBLES, C. I.; ARIAS, A.; HARDISSON, A.; RODRÍGUEZ-ALVAREZ, C.; SIERRA, A. Phytic acid level in wheat flours. Journal of Cereal Science, Manhattan, KS, v. 36, n. 1, p. 19-23, 2002.

FUKUJI, T. S.; FERREIRA, D. L.; SOARES, A. L.; PRETE, C. E. C.; IDA, E. I. Ácido fítico de híbridos de milho e alguns produtos industrializados. Acta Scientiarum. Agronomy, Maringá, v. 30, n. 1, p. 31-35, 2008.

GEBERT, S.; BEE, G.; PFIRTER, H. P.; WENK, C. Phytase and vitamin $\mathrm{E}$ in the feed of growing pigs: 1 . Influence on growth, mineral digestibility and fatty acid in digesta. Journal Animal Physiology and Animal Nutrition, Berlin, v. 81, n. 1, p. 9-19, 1999a.

Phytase and vitamin $\mathrm{E}$ in the feed of growing pigs: 2 . Influence on carcass characteristics, meat and fat quality. Journal Animal Physiology and Animal Nutrition, Berlin, v. 81, n. 1, p. 20-30, 1999 b.

GODOY, S.; HERNÁNDEZ, G.; CHICCO, C. Efecto de la suplementación de fitasa microbial en la utilización de fósforo fítico en pollos de engorde alimentados con dietas a base de maíz - soya. Revista Cientifica, Maracaibo, v. 12, n. 2, p. 519-523, 2002.

GRAF, E.; EATON, J. W. Effects of phytate on mineral bioavailability in mice. The Journal of Nutrition, Bethesda, v. 114, n. 7, p. 1192-1198, 1990.

GREINER, R.; CARLSSON, N. G.; ALMINGER, M. L. Stereospecificity of myo-inositol hexakisphosphate dephosphorylation by a phytate-degrading enzyme of Escherichia coli. Journal of Biotechnology, Bielefeld, v. 84, n. 1, p. 53-62, 2000.

HARBACH, A. P. R.; COSTA, M. C. R. da; SOARES, A. L.; BRIDI, A. M.; SHIMOKOMAKI, M.; SILVA, C. A. da; IDA, E. I. Dietary corn germ containing phytic acid prevents pork meat lipid oxidation while maintaining normal animal growth performance. Food Chemistry, Whiteknights, v. 100, n. 4, p. 1630-1633, 2007.

KASIM, A. B.; EDWARDS, H. M. The analysis for inositol phosphate forms in feed ingredients. Journal of the Science of Food and Agriculture, Davis, v. 76, n. 1, p. 1-9, 1998.

KESHAVARZ, K. Por qué es necessário emplear la fitase em la dieta de las ponedoras? Industria Avicola, Rockford, v. 46, n. 1, p. 13-14, 1999.

LEAL, E. S. Extração, obtenção e caracterização parcial de ácido fitico do germe grosso de milho e aplicação como antioxidante. 2000. Dissertação (Mestrado em Ciência de alimentos) - Universidade Estadual de Londrina, Londrina.

LEE, B. J.; HENDRICKS, D. G. Phytic acid protective effect against beef round muscle lipid peroxidation. Journal of Food Science, Raleigh, v. 60, n. 2, p. 241-244, 1995. 
LIU, Z.; CHENG, F.; ZHANG, G. Grain phytic acid content in japonica rice as affected by cultivar end environment and its relation to protein content. Food Chemistry, Whiteknights, v. 89, n. 1, p. 49-52, 2005.

MUNARO, F. A.; LÓPEZ, J.; TEIXEIRA, A. S.; RUTZ, F. Aumento da disponibilidade de fósforo fítico pela adição de fitase a rações para frangos de corte. Revista da Sociedade Brasileira de Zootecnia, Viçosa, MG, v. 25, n. 5, p. 921-931, 1996.

PILLAI, P. B.; O'CONNOR-DENNIE, T.; OWENS, C. M.; EMMERT, J. L. Efficacy of an escherichia coli phytase in broilers fed adequate or reduced phosphorus diets and its effect on carcass characteristics. Poultry Science, Champaign, v. 85, n. 10, p. 1737-1745, 2006.

PINTAR, J.; HOMEN, B.; GAZIĆ, K.; GRBEŠA, D.; SIKIRIĆ, M.; ČERNY, T. Effects of supplemental phytase on performance and tibia ash of broilers fed different cereals based diets. Czech Journal Animal Science, Prague, v. 49, n. 12, p. 542-548, 2004.

QIAN, H.; KORNEGAY, E. T.; CONNER, D. E. Adverse effects of wide calcium: phosphorus and calcium as influenced by microbial phytase, cholecalciferol diets. Poultry Science, Champaign, v. 76, n. 1, p. 36-47, 1996.

RAVINDRAN, V.; MOREL, P. C.; PARTRIDGE, G.; HRUBY, M.; SANDS, J. S. Influence of an Escherichia coli derived phytase on nutrient utilization in broiler starters fed diets containing varying concentrations of phytic acid. Poultry Science, Champaign, v. 85, n. 1, p. 82-89, 2006.

REZAEI, M.; BORBOR, S.; ZAGHARI, M.; TEIMOURI, A. Effect of phytase supplementation on nutrients availability and performance of broiler chicks. International Journal of Poultry Science, Lasani Town, v. 6, n. 1, p. 55-58, 2007.

ROSTAGNO, H. S.; ALBINO, L. F. T.; DONZELE, J. L.; GOMES, P. C.; FERREIRA, A. S.; OLIVEIRA, R. F.; LOPES, D. C. Tabelas brasileiras para aves e suínos: composição de alimentos e exigências nutricionais. 2. ed. Viçosa, MG: Universidade Federal de Viçosa, 2005.

SAKOMURA, N. K.; ROSTAGNO, H. S. Métodos de pesquisa em nutrição de monogástricos. Jaboticabal: FUNEP, 2007. $283 \mathrm{p}$.

SHELTON, J. L.; SOUTHERN, L. L.; LEMIEUXS, F. M.; BIDNER, T. D.; PAGE, T. G. Efects of microbial phytase, low calcium and phosphorus, and removing the dietary trace mineral premix on carcass traits, pork quality, plasma metabolites, and tissue mineral content in growing-finishig pig. Journal Animal Science, Madison, v. 82, n. 9, p. 2630-2639, 2004.

SOARES, A. L. Ação de ácido fítico e vitamina $E$ na oxidação lipídica e aroma de requentado em filés de peito de frango. 1998. Dissertação (Mestrado em Ciência de Alimentos) - Universidade Estadual de Londrina, Londrina.

SOARES, A. L.; OLIVO, R.; SHIMOKOMAKI, M.; IDA, E. I. Synergism between dietary vitamin e and exogenous phytic acid in prevention of warmed-overflavour development in chicken Pectoralis major M. Brazilian Archives of Biology and Technology, Curitiba, v. 47, n. 1, p. 57-62, 2004.

ST. ANGELO, A. J. Lipid oxidation in foods. Critical Review Food Science Nutrition, Cleveland, v. 36, n. 3, p. 175-224, 1996.

STAHL, C. H.; HAN, Y. M.; RONEKER, K. R. Phytase improves iron bioavailability for hemoglobin synthesis in young pigs. Journal of Animal Science, Madison, v. 77, n. 3, p. 2135-2142, 1999.

TARLADGIS, B. G.; PEARSON, A. M.; DUGAN JUNIOR, L. R. Chemistry of the 2-thiobarbituric test for determination of oxidative rancidity in foods. II. Formation of the TBA-malonaldehyde complex without acid-heat treatment. Journal of the Science of Food and Agriculture, Davis, v. 15, n. 9, p. 602-607, 1964.

TEJEDOR, A. A.; ALBINO, L. F. T.; ROSTAGNO, H. S. Efeito da adição da enzima fitase sobre o desempenho e a digestibilidade ileal de nutrientes. Revista Brasileira de Zootecnia, Viçosa, MG, v. 30, n. 3, p. 802-808, 2001.

UNIVERSIDADE FEDERAL DE VIÇOSA - UFV. SAEG - Sistema de análises estatísticas e genéticas. Versão 8.0. Viçosa, MG, 2005. 142 p.

VIEIRA, A. R.; RABELLO, C. B. V.; LUDKE, M. C. M. M.; DUTRA JÚNIOR, W. M.; TORRES, D. M.; LOPES, J. B. Efeito de diferentes níveis de inclusão de farelo de arroz em dietas suplementadas com fitase para frangos de corte. Acta Scientiarum. Animal Sciences, Maringá, v. 29, n. 3, p. 267-275, 2007.

XU, Y.; LIU, X.; PRESTWICH, G. D. Synthesis of phosphatase-resistant analogues of phytic acid (InsP6). Tetrahedron Letters, Oxford, v. 46, n. 48, p. 8311-8314, 2005. 